\title{
Erratum to: Study on the binding interaction between perfluoroalkyl acids and DNA
}

\author{
Jie Cao $・$ Yin Wei $\cdot$ Yan Cheng $\cdot$ Liang-Hong Guo
}

Published online: 14 June 2014

(C) Springer-Verlag Berlin Heidelberg 2014

Erratum to: Environ Sci Pollut Res (2013) 20:8355-8363

DOI 10.1007/s11356-013-1760-4

Prof. Liang-Hong Guo is added as the fourth author and the second corresponding author.

The online version of the original article can be found at http://dx.doi.org/ 10.1007/s11356-013-1760-4.

J. Cao

AQSIQ Key Laboratory of Drug Detection, Fujian International

Travel Healthcare Center, Fujian Entry-Exit Inspection and

Quarantine Bureau of P.R.C., Fujian 350001, China

Y. Wei $(\bowtie) \cdot$ L.-H. Guo $(\bowtie)$

State Key Laboratory of Environmental Chemistry and

Ecotoxicology, Research Center for Eco-environmental Sciences,

Chinese Academy of Sciences, P.O. Box 2871, Beijing 100085,

China

e-mail: weiyin@rcees.ac.cn

e-mail: LHGuo@rcees.ac.cn

Y. Cheng

Chinese Academy of Inspection \& Quarantine, No. 3A, North

Gaobeidian Road, Beijing 100123, China 